\title{
Asedio al cuento y a la novela*
}

\author{
Alberto Escobar
}

If 1 estudio del procedimiento expositivo permite inducir tendencias típiE cas en la evolución del cuento y de la novela. Sobre ésta se han efectuado investigaciones que falta iniciar acerca del cuento, para después establecer la relación entre ambos géneros. El presente ensayo pretende ser un aporte a esta tarea.

\section{Confusiones}

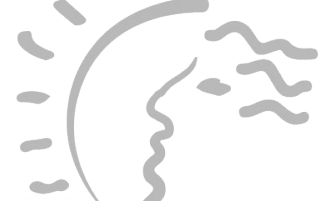

Agotada la "novedad" de los argumentos novelescos, el género concentró su atractivo en la expresión. La novela última procura dar importancia al actuar, al hacer; procural mover lescpersonajeseconamayor afán que antes. Y en tal forma, que ellos șejindependizandè quien los serea y se presentan solos, yiviendo como debe hacerlo el tipo humano que encarna. Fuera de uso queda entonces la explicación ambiental, que corresponde a los primeros estadios novelísticos, y la misma noticia psicológica, cuyo paulatino destierro inició Dostoievsky. El comportamiento del sujeto, sin comentarios, debía proporcionar elementos sobre la modalidad anímica y las inclinaciones personales, apareciendo lo que se ha convenido llamar "técnica objetiva".

- Letras Peruanas, $\mathrm{N}^{\circ}$ 2, agosto de 1951. 
Durante las últimas décadas se ha publicado numeroso material, que, por lo variado y por los extraordinarios recursos que utiliza, confunde y entremezcla los sistemas que denominaríamos tradicionales. A tal extremo que, al estudiar las influencias de dichas modalidades en las formas expositivas de la novela contemporánea, quien sabe si advirtamos lo narrativo "remozado", relegando maneras presentativas, otrora vigentes en modo preferencial, pero que hoy se asocian a la primitiva expresión, fervorosamente adoptada en ambas postguerras. De Los hermanos Karamazov al Gran dinero; de Cemento a las Praderas del cielo; de Faulkner a Sartre o a Moravia, sin duda, se viene plasmando un gran movimiento transformador de la técnica novelística.

Novela y cuento difieren, pese a novísimas vecindades, en el procedimiento expositivo. El último mantiene su esencia narrativa, no obstante concesiones hechas por autores recientes y al empleo insólito del diálogo y de las conversaciones múltiples que, en oportunidades, disimulan la forma narrativa. Pero, ¿adopta esa actitud, como la novela, por querer concentrar la atención en un acontecer indirecto, o en un acontecimiento indirectamente abordado? Creo que existe otro motivo. Si en la novela se dialoga para que el personaje logre autodefinirse y construya un suceder literario, por abandono del argumento, en el cuento los personajes dialogan para incidir en el mismo. Lo cual es ya diferencia notoria en el uso de los eslabones que constituye la conversación. Razón ésta por la que el auténticơ monólogo ha pretendido introducirse en muy escasas ocasiones en el cuento. En éste, la finalidad de la voz es divulgar el tema, de acuerdo con la extensión de qa obra y-sus dernâs notas peculiares. Y como tal, quien escribe se pone'er boua déund de Ios personajes y narra. Siempre hay, pues, narración, (forma común en la cuentística latinoamericana). En ambos géneros, sin pretender identificarlos, nótase el apogeo de tendencias narrativas. Coincide esta situación con periodos históricos anunciadores de próximos estados, ante los cuales el temperamento artístico se ve forzado a narrar lo que hubo y lo que vendrá. El tono de profecía, el de balance, la admonición, se deciden con frecuencia por las versiones narradas logrando convivir de muy feliz manera. Y, asimismo, podría pasar inadvertido al lector común el extraño cruce e intercambio de técnicas expositivas entre cuento y novela.

\section{Ámbito}

La divergencia más saltante entre uno y otra es, para la generalidad, la diferencia de extensión. Pedro Selva cree observar en las dimensiones una 
síntesis de los factores que tipifican cada género; y la más simple deducción concluirá enseñándonos que una novela desarrolla tema más amplio que el desenvuelto en un cuento. En éste lo importante es el suceso, nada más; sólo un aspecto, una fase muy breve de algo que puede estimarse como de un ciclo mayor. Pero, ¿debe creerse acaso que la novela surge por acumulación de cuentos? De ningún modo, ya que si es cierto que sobre un incidente, que bien podría ser parte integrante de un argumento novelesco, se construye un cuento, dicho incidente es tratado dentro de la tónica propia del género. Entonces se habrá conseguido el cuento, no sólo por referir un suceso, una faceta de algo más amplio, sino porque el fondo se avino a la forma y a la tonalidad del género. Igualmente, rechazamos el supuesto de que un fondo novelesco pueda someterse a los cánones del cuento y conseguir serlo, seguros que la naturaleza de éste no acepta ni conviene con tipos de argumento que no reunen condiciones especiales. La reducción al mínimo de un tema novelesco no conseguiría otro fruto que una novela corta, con casi la totalidad de atributos de su hermana mayor.

El cuento, hemos repetido, en contraste con la novela, disfruta de afinidad por las proporciones reducidas, mientras que ella necesita amplitud. Requiere escenarios más dilatados para mover sus personajes. Sin desplazarse, en idas y vueltas a pie firme, amplía su duración. La novela, ha dicho Ortega y Gasset, es "atmosférica". Crea, vive, urge una atmósfera vital. Su afán reconstructor, arquitectónico, su abrazo amoroso de volúmenes, la incitan periódicamente a la tareă de estructurar amabientes. Juega en ellos; y, para los mismos, se ha notådo quereclamaltratos derealidad transplantada. Crea los planos de esa ciudadela ficticia, y una vez levantada, se regocija al hacernos recorrerla. Su proceder es la insistencia, el reconocimiento, sabémoslo en Proust, en Joyce, y de modo menos premeditado y más agradable en Huxley. La atmósfera novelesca recoge y asimila elementos sociológicos, constituyendo factor poderoso en la "vitalización" de las novelas de todas las épocas. Poco o nada, de esto puede encontrarse en los cuentos, y de haberlo, bien lejos está de constituir una costumbre.

\section{Noticia del ritmo}

Comprobado cómo y qué abordan cuento y novela, débese agregar qué ritmo utilizan. Intentos de clasificación como el actual, inciden con frecuencia en algunas notas, por considerarlas generadoras de posteriores apreciaciones. 
Así, conociendo que el cuento trata un hecho concreto, que utiliza la narración, y que no es muy extenso, podemos avanzar hasta sostener que emplea ritmo acelerado. Es decir, no busca la prolongación ni el detalle -placidez intermedia-; su proceso directo agota velozmente lo por narrar y concluye. La novela dispone de cánones opuestos. Si su ámbito es más grande, si la técnica objetiva la domina, la novela debe ser lenta. (Y, a su hora, contribuyó mucho el afán presentativo). Pero no queda ahí, porque los novelistas procuran hacerla detallando circunstancias. Tratan de adjetivarla, y así, la tornan "retardataria", "morosa" en el relato. Calificación específica de su lentitud. Tal ocurre, vergibracia, en el Ulises, que hace exclamar a Jung: "735 páginas todo ello para llegar a expresar de un modo más feroz, el vacío asfixiante, sentido o estirado hasta lo insoportable. Este vacío, absolutamente desesperado, es la técnica del libro entero. No sólo empieza y acaba en nada, sino que se compone también de pura nada". La técnica del escritor se dedicó a prolongar el relato de lo ocurrido en unas cuantas horas y, lo que podría considerarse caso extremo en Joyce, no desaparece en ningún escritor dedicado a la novela. Tal postergación, tal renuncia, afán de dar a los hechos en su aspecto expositivo un ritmo tardío, es cualidad, o defecto, novelístico. El "tempo lento", que difiere del tiempo, no es la duración material que han necesitado los acontecimientos, no la posibilidad ideal que deja entrever el autor, sino el dar y no dar, el decir y retener que conviene por esa morosidad, y se irá determinando como un "tempo lento" musical. Cuando K. presencia el alegato del fogonero, hay un tiempo material: el de los hechos supuestos. Hay también el que K hubiera deseado combinar cothe una situaciont tiempo-virtual. Y existe, por último, el que transcüre lentacyidelorosamentesen virtud del relato que desenvuelve Kafka en América. Como él, los más selectos ejemplos de la novelística. Proust empleó el mismo método, vestido de recuerdos y memoria, no de otra manera sería factible su asombroso proceder diagnóstico, casi clínico. Empedernido hurgador del tiempo, nos pierde en sus laberintos, domina las leyes del "tempo", y consigue equilibrar su concepción subjetiva, al mantenerse en igual plano, forzoso, de objetividad. Quede claro que la velocidad del cuento es contraria al ritmo de la novela. Selva compara la última con el eje horizontal en el que giran las ruedas de una carreta cuando avanza. Y al cuento, con el eje del trompo, "vertical", soportando el impulso de su bailar incontenible. Recordémoslo, porque en tránsitos tan continuos y juicios contradictorios, el ritmo se empecina por mantener la hidalguía de los géneros. 


\section{Esquema y transparencia}

Al iniciar un cuento los autores saben, necesariamente, de qué tratará y en qué forma ha de terminar. El escritor que domina la técnica, es diestro en el arte de conseguir adecuada "composición". Es claro, intuye la estructura -sin imaginar previamente un molde rígido, orientándose decidido a la tarea. Edgar A. Poe fue partidario de procedimiento análogo cuando al referirse al método, dijo: "Para que un plan merezca el nombre de tal, debe haber sido cuidadosamente elaborado para preparar el desenlace, antes de que la pluma se pose en el papel". Así, el escritor norteamericano asoció sus obras al método de "fondo y efecto" que lo consagraría. Para el lector superficial la construcción minuciosa a que sometió sus producciones el autor de El cuervo, carece de importancia, aunque al leerlo sea incapaz de soslayar su poderosa influencia. El novelista, de seguro, toma la materia e ignora cómo y cuándo ha de concluir. No significa que desconozca el asunto que prepara. No. Pero lo flexible de las exigencias novelísticas, su anhelo de veracidad, producen en el autor falta de noción acerca del momento en el que debe terminar. El final -para él y para la obra, no así para el lector- carece de importancia, como el principio; ambos son pretextos que sirven a lo intermedio. Y lo que se encuentra entre los extremos no es sino suceder, o sucesión de aconteceres, desarrollo de todas las posibiliidades del "tempo lento". La novela, dijimos, vive de la observación, teje y deshace cuadros, aumenta o disminuye en intensidad y, conforme convenga, provoca en sus personajes cambios psicológicos violentos o leves. A veces, easi puede decirse que desorienta al lector, agobiándolo en contraposicionescy planos diversos. Todo esto ocurre porque la novela esquematiza a cada paso, continuamente. Y sin embargo, no es un esquema genérico. Más adelante veremos por qué. Empero, si la novela esquematiza, el cuento es esquemático. Los mejores cuentos sorprenden por lo simple de su construcción, como si fueran hechos de dos o tres brochazos. Tienen la virtud de ser transparentes. El mérito resalta conforme se aprecia esta cualidad de llegar al lector para seducirlo con el trazo de unas líneas, simples, pero llenas de vida y colorido.

\section{Observación y novela}

Al considerar la velocidad narrativa de la novela, incluíamos como una de sus causas, la necesidad de alimentarse en el detalle. Con certeza, la novela es buena observadora -en especial, de serlo el novelista-, y abunda en esmero 
por captar incidentes, datos mínimos, por percibir circunstancias determinadas. En esa forma va descubriéndonos sus personajes, sobre todo cuando trata de tipificar los rasgos subjetivos. La observación de lo externo primó cuando el interés por la aventura, por la trama, superaba la figura del personaje. La novela contemporánea ha ido diluyendo la trabazón objetiva, y al hacerlo, ha crecido el interés por el panorama psíquico y su compleja urbe de posibilidades.

Dámaso Alonso quiere ver en la primitiva novela española la presencia de lo que él llama "realismo de almas", como anterior "al realismo de cosas", apoyando su tesis en la perspectiva sui géneris que la literatura hispánica ofrece, comparada con el resto de las literaturas nacionales de Europa. Por ello, nosotros creemos entender que esta presencia del "realismo de almas", atisbo del dominio anímico, es valiosa relacionándola con los escritores extranjeros de la época. Quedara en esa forma testimonio de la agudeza derrochada por El lazarillo, junto a los intentos de publicaciones mediocres, y a las tendencias sentimental, caballeresca, pastoril y morisca o histórica, dando manifestación de uno u otro matiz, ante autores como Chaucer o Boccaccio. No estimamos haya sido intención de Dámaso Alonso, observar en abstracto el proceso de lo material y psicológico en la novela española. En la que si bien reconocemos que en sus albores ensaya el trato de las almas, en algunas obras, no podemos suprimir la mayoría de lo vigente en la época que determina el apogeo del realismo material, pese al contrasentido. No pretendemos que en un momento todas las producciones incidan en el ambiente anímico, y que en otro instante, distinto al interior, sea el murfo externo el que domine. No. De común lógrase una combinación, y de ésta, o dentro de la misma, puede inducirse una u otra corriente. Conviene recordar, que el hombre descubre su yo íntimo después de entrar en relación y haber asimilado el medio ambiente. Avanza de la pluralidad a lo individual, de afuera hacia adentro. Por ahora, limitémonos a establecer que la facilidad novelesca para convivir con el detalle, existe en cualesquiera de los realismos. En las dos direcciones el escritor debe acudir a pormenorizar. Un novelista que no lo hace perjudica su obra en la apreciación que de ella puede tener el lector. Y quizás sea esa condición una de las pocas, con el ritmo, que no ha variado en la historia de la novela. No resta duda, la novela necesita pormenorizar. Lo hace, con el fin de conseguir lo que hemos venido llamando "atmósfera". Para lograrlo acude al detalle, a la observación de aspectos postergados en múltiples oportunidades, sin que por ello sean considerados menos reales. La novela es detallista frente al cuento que no se preocupa, ni atiende pormenores. La estructura y 
técnica del cuento no reparan en minucias, no derrochan espacio o tiempo. Acaso la velocidad borre ocasión de prodigarlos.

Los cuentistas de Latinoamérica -pocos en las nuevas promocionesretratan el paisaje y, algunos llegan a enamorarse de él. Ocurre fenómeno igual con los novelistas quienes continúan descubriendo escenarios naturales. ¿Existe acaso una misma razón? -En la novela es tendencia vuelta costumbre: acumular notas por la escrupulosa observación de los transfondos y escenarios, en afán de crear el ambiente. Además, no olvidemos que la novela latinoamericana se debate por abandonar el campo de las novelas "pasivas" $y$, en tanto lo consiga definitivamente, seremos víctimas de autores descriptivos y aburridos; pese a escasas y meritorias excepciones. En el cuento la inclinación responde a otros motivos. El paisaje desarrolla otra tarea. No es lo accesorio, ni tiene la importancia del tablado o del telón. Cuando lo inunda, lo hace en la temática, en el personaje configurado por sus particulares caracteres, o al que tal vez ha desfigurado. El paisaje se ha ido adentrando -vale esto para Latinoamérica y sus cuentos-como un personaje del ambiente. Las descripciones son breves; sin embargo, el paisaje las sobrevive. Cuando equivocadamente el autor las acentúa, lo natural atrofia la narración y aparecen las estampas y los cuadros.

Hay también en el cuento visión sintética; se nutre de ellas. Aprehende originalmente lo sustantivo, y luego lo cubre con vestimenta de símbolo, de fantasía. Reduce lo que es factible dilatar $\mathrm{g}$, enemanos de maestros como Guy de Maupassant, su sintetismopconviátésecenespectáculo objetivado. Tomemos un ejemplo más próximo a nosotros, aquella novela corta de José Diez Canseco: Suzy. La intención del autor fue reflejar una edad de pureza, bella e ingenua como su inolvidable primita. En la primera parte agota la descripción del paisaje y costumbres, con cierta morosidad. Pero cuando deja las descripciones y decide presentar, cuando corren los diálogos palomillas, cuando riñen los niños con todo lo sabroso de un lenguaje adaptado a su edad; cuando lloran, cuando ríen, cuando se hablan a solas, Diez Canseco consigue lo buscado. Y lo alcanza con holgura. Quiero referirme a un momento preciso, al diálogo que sostiene Pepe con Suzy, cuando descienden al viejo sótano: el niño, enamorado de su prima y en víspera de viaje, no desea partir sin probar el cariño en los labios de Suzy.

Le ruega con voz delatora y ansiosa; ella se resiste, se asombra, lo increpa. Y él-precocidad del sexo- le ofrece como estímulo unos caramelos 
que lleva en el bolsillo de la camisa. Ella se niega, tiembla; pero sus cuerpecitos estaban muy juntos, y Pepe besa los labios carnosos y quietos de Suzy. Cuando suben al lugar donde esperan los demás niños, él se aisla ruborizado de su primera audacia amorosa. Echa a correr y, al llegar a la verja de la casa, se percata que alguien lo sigue. Piensa huir, pero es inútil, una vocecilla agitada le reclama:... ¿y mis caramelos? -Esta sola escena habría conseguido en un cuento todo el efecto que la novela nos procura. Podemos precisar, ahora, más nítida, la escasa capacidad sintética de la novela. No se arguya sobre la propiedad del ejemplo; sería igual con la Comedia humana o La montaña mágica. De la novela dijimos que esquematiza sin llegar a construir un esquema general, claro, estable. Con los análisis se ahoga resolviendo el cómo, el por qué, el cuándo, y el dónde de sus personajes. Dilúyese facultada por su control del pormenor, y así, esquematizando, no llega a ser esquemática, porque sufre la tortura del análisis.

El cuento es esquemático y sintético; concibe, dibuja y concreta. La novela, en especial la europea última, se angustia -artificial, "metafísicamente"- con los problemas del hombre, los desbroza hasta sentirse agónica perenne, y en muchos casos pretende resolverlos en sublimaciones negativas. El cuento, en tanto, más parece que sonríe, escéptico, y cuando se lamenta lo hace sin desvaríos, despreocupadamente, con la temeridad y franca soltura de la gente aldeana. De la manera citada el planteamiento se define y resume con mejor claridad. La novela no puede ir más allá de la esquematización formal. Es en lo externo, en la forma, donde finaliza su atuendo gráfico, como los dibujos que representan fos sisfemas integral por conseguir felicidad didáctica, pero, sin alterar ni relacionarse mínimamente con los verdaderos sistemas. El cuento esquematiza, mas no la forma. Lo hace con la acción. Goza, podríamos decir, de una facultad distributiva, que administra adecuadamente los impulsos y frenos de la acción global, y del actuar individual de los personajes. Y, a diferencia de las reproducciones estáticas y semajentes, el cuento requeriría instrumento análogo al aparato circulatorio -en el movimiento constante- para reemplazar simbólicamente la esquematización del actuar. Reelaborando a nuestra conveniencia, la definición de un prestigioso crítico hispano, podríamos decir que si la novela esquematiza el estar, el cuento esquematiza el ser. 
Cuando el lector inicia un cuento va recorriéndolo y antes de terminar, intuye en el acontecer la necesidad de algo importante. Es más, se aviene al hecho como cuerpo abandonado que presiente en su caída la inminencia del suelo. Algo debe ocurrir forzosamente, pero lo imprevisto le otorgará vigor, producirá una especie de contracción que se conoce como el "efecto final".

Los cuentistas latinoamericanos dominan la técnica del cuento en forma incompleta. Digo así, porque las producciones que logran definir se pueden calificar como "embriones de novela". Hay tal conclusión entre una y otra actividad que, en muchos casos, iniciando un camino se concluye en el otro. Rómulo Gallegos, verbigracia, empieza en el cuento para terminar en Doña Bárbara, en Cantaclaro, en Pobre negro. Y es que en este escritor como en tantos de América, los cuentos se convierten en prácticas, en antecedentes de sus novelas. Y a tales cápsulas que la falta de aliento pasmó, se denomina cuentos. El fenómeno aparece claro en Rebelión, el más difundido cuento de Gallegos, y Rebelión, en buena ley, en novela. Corta si se quiere, pero pura novela. ¿Y que otra cosa puede decirse de Abraham Valdelomar?; el cuento, "nuestro cuento sudamericano", fermentó demasiado en El caballero Carmelo. Vale reseñar que el tránsito también se ha producido en inverso sentido, y consecuencia de estos trajines en la despreocupación de los autores, que dudarían al preguntárseles qué escriben, si cuento o novela. Algunos desestiman -en su confusión-1 el valoreategórico quế concede al cuento el efecto final. Suponen que éste pueđeuterminàr đasín no_más, de cualquier forma, comúnmente, como lo hace la novela, sin traicionarse en nada. Otros, en cambio, dan vigor a sus narraciones aprovechando la importancia que asume un relato hábilmente concluido.

Las acciones finales permiten un intento de clasificación. Elementalmente: simples y compuestas. Entre las primeras ubico la que utiliza César Vallejo en su relato Los Caynas, que invita - sin establecer influencias- a recordar $E l$ informe para una academia de Kafka. El desvanecimiento de la verdad supuesta hasta que el enfermero recluye al loco que narraba cómo su pueblo ingresó a un estado de simiedad, da un vuelco e impresiona efectistamente al lector. Por una sola vez, con un solo impulso, -directamente- consigue su propósito. Tal el primer caso. 
Como segundo ejemplo conviene El alfiler de Ventura García Calderón. Relato hermoso, con gran soltura de lenguaje; matiz de vocablos regionales sin abuso de ellos, vivacidad, rapidez, sintetismo, unidad, y lo que más nos importa ahora, un diferente efecto final. Al confiar Timoteo Mondaraz a su yerno, que él guarda el alfiler con el que éste último asesinó a su mala esposa, hija del viejo, se produce el primer estado. Luego, cuando consiente entregarle a su segunda hija para que contraiga nuevas nupcias, y le da el alfiler diciéndole: "Toma, si esta también te engaña haz lo mismo. Como otorgaban los abuelos la espada al nuevo caballero", se completa el segundo instante de la acción terminal doble, compuesta. En ambos párrafos es el padre quien provoca el efecto, cuando descubre, cuando aprueba, y finalmente cuando aconseja al joven hacendado. Anotamos así que gran parte de la belleza del cuento se afianza en la destreza del escritor, para hacer coincidir en el desenlace la energía de lo narrado, como extrema e íntima convulsión de autor, personaje y lector.

Cabe definir dos nuevas modalidades que no excluyen las anteriores, sino que necesariamente habrán de darse con una, u otra forma, acompañando a los finales simples o compuestos. Adjetivándolos. Los efectos deberán ser ora expresos, ora tácitos. O lo que es lo mismo activos y pasivos.

La literatura de nuestra América mestiza, como el arte americano en general, se ha convulsjonado íntimamente con el padecer azaroso de nuestros países. La cuentística ofrece por Elf infinidad de obras que son la protesta del hombre ante sitúacibies-politico-sociales vavasalladoras de la dignidad humana. Por esta condición que hermana el arte con la realidad, es más fácil entender el sentido y la percepción de los cuentos americanos. Sin proponérselo, muchos autores han cumplido la ruta escogida por Edgar A. Poe, cuando destina al fracaso los cuentos que no producen efecto en el lector. La acción expresa, activa, procura un atacar directo a la sensibilidad del que lee, verbigracia las narraciones esbozadas en líneas superiores. Complementariamente ocasionan una respuesta que podemos calificar de comprensión pasiva en el lector. Es decir, el cuento finaliza con la última frase, resolviéndo sus posibilidades que son aceptadas como hecho concluido.

Otras narraciones terminan en forma dubitativa, invocando la meditación, con planteamientos o situaciones que forzosamente se acogen a la tarea complementaria, recreativa, del que lee. Se trata del efecto pasivo que busca la posición activa del lector, al que llega en forma indirecta y distinta a como 
lo hacen los ya estudiados. Aquellas producciones en las que los autores desfogan pesimismo, carencia de fe por un futuro mejor, en lugar de contagiarnos nos empujan, mágicamente, a la protesta, a la reconstrucción de los derechos, a la búsqueda de una sociedad más humana por justa. No es sin embargo, el efecto pasivo, producto fértil, únicamente, en cuentos cuya temática aborde el problema social. En esa actitud evidénciase, es cierto, con mayor altura, pero sin que llegue a constituirse cuestión determinante de una a otro, premisa sine qua non. Lo es, cuando se escriben totalmente imbuidos del ánimo que una decidida convicción estimula, y se obtiene lo que José María Arguedas logró en Agua, al sentirse poseído del "odio puro, aquel que brota de los amores universales". Porque es la realidad ardorosa que nos envuelve agotadoramente, mientras tarda el códice que habrá de descifrar nuestros contrasentidos sociales. Pero, cuando el cuento desenvuelve un tema en el que el término conduce a una situación análoga al comienzo, y en cualquier asunto, de darse el efecto pasivo, es también el lector quien inicia la trayectoria para quebrar el círculo formado. Puede dar fe Max Nottingger, recordando aún en toda reunión social; o ¿por qué no preguntárselo a aquel personaje de Manuel Beingolea, que guarda la felicidad en una caja vacía de jabón de Windsor?

Sabemos que el efecto compuesto es el que consta de más de una acción. Estas, podemos observarlas en diversas modalidades. La literatura hindú ofrece narraciones con varios efectos que están comprendidos dentro de diferentes relatos que incluyen unosGabotros. Y toddos. Se solucionan al mismo tiempo, o paulatinamente, peropondependencia de on acto principal. La reina y el pescado riente es el caso típico del cuento hindú con varias soluciones que se identifican en una sola dentro del tiempo ideal. En la actualidad está fuera de costumbre ese tipo de cuentos, pero con dicha orientación todavía se conciben narraciones que poseen efectos compuestos, sucesivos o simultáneos. Clemente Palma ha escrito un relato tan conocido como Los ojos de Lina, en el que la acción se reduce al hecho que narra el personaje masculino. La novia de Jim ejercía una influencia perturbadora en el ánimo de éste, y aun cuando se amaban decididamente, los ojos de Lina transtornaban en forma inevitable a Jim. Y Jim cuenta cómo Lina le ofrece los ojos extraídos de sus órbitas como regalo de boda. Pero cuando ha conseguido el efecto tremendo de ese gesto trágico, Jim se ríe, y responsabiliza de la historia a una botella de ginebra. Los instantes de la acción se presentan en forma notoria, se trata casi de un "uno, dos" de "tempo" musical. Palma ha combinado la intensidad de una experiencia romántica con la belleza sutil de su mentira entretenida. 
No poseen los dos toques la misma intención, el uno tiende a lo real, mientras el otro se evade hacia la fantasía. El segundo descompone lo que el primero fabricó, de no ser así, habríamos descendido al folletín sentimental.

El cuento La alcancía de barro negro, del escritor venezolano Raúl Valera, permite apreciar el efecto final compuesto en forma simultánea. Es claro que materialmente una cláusula estará después que la otra, pero dentro del tiempo ideal de la obra, las soluciones se producen simultáneamente. Es así como Pablo, el hombre que vivía agobiado por dos problemas fundamentales e insolubles: la esterilidad de la mujer y la infecundidad de la tierra, va consumiendo su vivir monótono en lucha continua con la naturaleza. El suelo es incapaz de producir por falta de riego y la mujer para darle descendencia; ni siquiera puede aportar un consejo cuando la urgencia de dinero lo aniquila. Y así, los dos platos de un mismo tema, subsisten hasta un día que, para su sorpresa, al mirar la línea blanca del camisón de Josefa descubre el perfil de la maternidad. Y mientras ella se toca instintivamente y le entrega una alcancía de barro, con el dinero que durante quince años depositó piadosamente, para cuando llegara ese momento de su reivindicación, al correr las monedas por el suelo, libres de su apretada casa, "se oyó como el caer de una fruta pesada. Luego otra, el viento silbó hondamente, había comenzado a llover. Era como si la alcancía del cielo se estrellase contra la tierra”. El personaje unifica sus lados en dos emociones que son una misma. Mujer y tierra, hijo y lluvia, como un solo problema desarrollado y resuelto simultáneamente.

Si en Los ojos de Lina Pu quiebra lia continuidad del espacio-tiempo, en La alcancía de barro negro ésta se mantiene, diría que aun se estrecha. Del efecto condicionado, tan grato a las literaturas hindú y china, al sucesivo de impulsos visibles; y del simultáneo convergente en términos plurales, a la narración que termina llanamente, existen todas las variantes y proporciones que imaginariamente crean los autores. Empero, también abunda el tipo de relato sin satisfacer las cláusulas mínimas que todo cuento debe llenar, no por ausencia de condiciones en el escritor, que sería arbitrario decir esto de Abraham Valdelomar, (quien además tiene magníficos cuentos); o de López Albújar, juez y maestro por esencia, que en sus Cuentos andinos y en sus Nuevos cuentos andinos satisface una disimulada vocación por el ensayo o por la biografía novelesca. Y como ellos, numerosos autores del Perú y de América. 
En la última nota de esta sección señalaremos las características de cuento y novela, referidas a la modalidad expansiva en función del argumento, de lo tramado, y de la forma como se va modelando esa urdimbre. En este punto convergen todos los anteriores; se plasma una consecuencia fácilmente razonable al análisis. El proceso que desarrolla una novela vive sujeto a la fuerza centrífuga de su desbordable impulso interior. Comienza en un supuesto determinado, y a la vez determinante, porque es el inicio de un espiral cuyo ascenso con círculos de amplitud mayor, se acrecienta en forma paulatina. La potencia reprimida rebasa los límites iniciales y, en suave crescendo, prolóngase cual cono de luz que nace en el vértice, para ir difundiendo claridad sobre los objetos que restan entre los lados. En El proceso de Kafka, por ejemplo, el desarrollo se alcanza después de una premisa consignada al empezar la obra. José $\mathrm{K}$ es inocente. Inocencia que nada ha de valer, y pese a la cual será juzgado y sufrirá la muerte por un delito, tan desconocido como el tribunal que lo sentencia. Sobre una base estrecha va construyéndose amplia cima, y la novela accede placentera a estos impulsos. ¿Hace el cuento lo mismo? Impresiona su práctica al extremo de diferenciarlo contrariamente. Si la novela presenta un espiral en crecimiento, el cuento, utilizando ejemplo análogo, no es sino un espiral que decrece. Que iniciando el recorrido en la parte superior, disminuye el ámbito primitivo hasta centrar en un punto. Aparenta, el cono invertido, y sigue la dirección de su vértice, esta vez para abajo. La base no es amplia, puesto que no es cafacteristica del géneroagotar las circunstancias, o utilizar extensos materuales. Puccinelli Converso"

Héctor Velarde, junto a crónicas y relatos simples, ha dibujado cuentos de grato sabor cosmopolita. Su imaginación es puerto donde tocan las banderas más disímiles, e irónica la expresión de sus páginas que, sin haberse propuesto jamás ese filosofismo que algunos le atribuyen, (y que los estudiantes de filosofía rechazan), torna al cuento procurador de moraleja y hondura reflexiva. Trabaja con cualesquier argumentos y nunca nos dice la lección. El lector debe aprehenderla en ese resaborear, infalible varadero al que nos llevan las obras de Velarde, y en la forzada detención ante aquella ironía suya, algo a lo Huxley del Contrapunto, que va asimilándose como impresión fugaz de lo intangible por cierto. El autor de Kikif, de El circo de Pitágoras, del Breviario de arquitectura, o del tratado de Geometría descriptiva, cuando hace cuentos siempre deja la impresión de sonreír. Y sus cuentos son eso: evasión de una continuidad suspendida por la risa. Esta particular manera es 
causa de que lo hayamos escogido para ejemplificar la nota que trata de la expansión en la novela y en el cuento.

Entre las narraciones del constructor que levantó La cortina de lata bastante conocida y antigua es In Corium. Aquella sociedad de filósofos que buscaban la verdad y, que en tal trance, precisaban desnudarse hasta quedar "en cueros", que era la voz y la actitud de orden y de sinceridad. Reunión a la que por satisfacer un gesto curioso llegó el personaje, y en la que, pese al asombro propio y de alguno de los extraños filósofos, tuvo que permanecer accediendo a la gentil solicitud de Pepeles, teósofo, maestro, y director de debates. Así, en forma paulatina, mientras va adentrándose por las intenciones y opinión de sus invitantes, el personaje despójase de la indumentaria y apenas si discurre ante la nutrida argumentación de Pepeles. Pero, los peros de siempre, cuando topa al convencimiento, siente frío y empieza a preocuparse. Nuestro actor da tres estornudos y se despierta "totalmente destapado sobre la cama".

La intención, el sentido de ruptura, el retraerse hasta un punto, la modalidad en sí, aparecen claros. Al concluir el sueño, lo imaginado se escapa por el embudo de la fantasía. La novela derrama; el cuento absorbe; concentra, se vale de la fuerza centrípeta. No pueden llevar la misma dirección. Quien sabe si en algún lugar se crucen. Quien sabe si al fin, a fuerza de hallarse tantas veces, decidantiniciar comủn

\section{"Jorge Puccinelli Converso"}

